\title{
IMPLEMENTASI DAN PENGUJIAN SISTEM INFORMASI PENGADUAN INVENTARIS KELAS
}

\author{
I Gusti Ngurah Anom Cahyadi Putra ${ }^{1)}$ Agus Tommy Adi Prawira Kusuma ${ }^{2)}$ \\ Program Studi Sistem Informasi, Fakultas Ilmu Kesehatan Sains dan Teknologi 1) 2) \\ Universitas Dhyana Pura, Badung, Bali \\ anomcahyadi@undhirabali.ac.id ${ }^{1)}$ agustommyadi@undhirabali.ac.id ${ }^{2)}$
}

\begin{abstract}
Class is an important inventory in lectures. A comfortable class will make the lecture atmosphere run well and effectively. In the classroom there are several facilities that support lectures, namely chairs, tables, LCDs, projectors, air conditioners, lights, LCD cables, whiteboards, erasers and wall clocks. If one of the facilities is damaged, it will disturb the comfort of the lecture. At present there has been a needs analysis and design of a class inventory inventory information system that produces a prototype system.From these problems, it is necessary to proceed to the next stage, namely the implementation and testing stages. The implementation stage is an advanced stage after analysis and design. At this stage will be analyzed the hardware and software requirements to determine the system requirements that will be applied to the internet. This research was conducted with methods of observation, interviews, design analysis, design design, implementation and system testing. This study produced a class inventory information system that had been applied to the internet and could be used by lecturers to report class conditions. The system can be used to accommodate complaints about class facilities and infrastructure and provide class inventory information.
\end{abstract}

Keywords: inventory, information systems, implementation

\begin{abstract}
ABSTRAK
Kelas merupakan salah satu inventaris penting dalam perkuliahan. Kelas yang nyaman akan membuat suasana perkuliahan berjalan baik dan efektif. Di dalam kelas terdapat beberapa sarana yang mendukung perkuliahan yaitu kursi, meja, lcd, proyektor, ac, lampu, kabel lcd, papan tulis, penghapus dan jam dinding. Apabila salah satu sarana rusak maka akan mengganggu kenyamanan perkuliahan. Saat ini telah dilakukan analisis kebutuhan dan perancangan sistem informasi pengaduan inventaris kelas yang menghasilkan sebuah purwarupa sistem. Dari permasalahan tersebut sehingga perlu dilanjutkan ke tahapan berikutnya yaitu tahapan implementasi dan pengujian. Tahapan implementasi merupakan tahapan lanjutan setelah analisis dan perancangan. Pada tahapan ini akan di analisis kebutuhan hardware dan software untuk mengetahui kebutuhan sistem yang akan diterapkan ke internet. Penelitian ini dilakukan dengan metode observasi, wawancara, analisis desain, perancangan desain, implementasi dan pengujian sistem. Penelitian ini menghasilkan sebuah sistem informasi inventaris kelas yang telah diterapkan ke internet dan bisa digunakan oleh dosen untuk melaporkan kondisi kelas. Sistem dapat digunakan untuk menampung pengaduan tentang sarana dan prasarana kelas dan menyediakan informasi inventaris kelas.
\end{abstract}

Kata kunci : inventaris, sistem informasi, implementasi 


\section{PENDAHULUAN}

Kelas merupakan salah satu inventaris penting dalam perkuliahan. Kelas yang nyaman akan membuat suasana perkuliahan berjalan baik dan efektif. Di dalam kelas terdapat beberapa sarana yang mendukung perkuliahan yaitu kursi, lcd proyektor, ac, jam dinding, meja, papan tulis, dan penghapus.

Apabila salah satu sarana rusak maka akan mengganggu kenyamanan perkuliahan. Saat ini dosen yang menggunakan ruang kelas apabila menemui kerusakan sarana kelas hanya bisa mengadukan secara manual ke bagian teknisi. Hal tersebut tentu akan membutuhkan waktu yang cukup lama. Pada universitas Dhyana Pura di gedung D yang digunakan oleh fakultas ilmu kesehatan sains dan teknologi memiliki beberapa ruang kelas dan satu laboratorium komputer. Bagi teknisi pengawasan terhadap kondisi sarana dan prasarana kelas yang masih manual sangat menyulitkan dan membutuhkan waktu.

Dibutuhkan personil teknisi yang banyak agar bisa mengawasi semua kondisi sarana kelas secara efektif dan efisien. Penelitian sebelumnya yang sudah dilakukan adalah tahapan analisis dan perancangan sistem sehingga menghasilkan sebuah purwarupa sistem informasi.

Perkembangan teknologi informasi saat ini sangat terasa manfaatnya dalam membantu permasalahan dalam suatu proses kegiatan bisnis, untuk itu perlu dikembangkan ke tahapan implementasi agar sistem dapat digunakan. Sistem informasi yang berkembang saat ini adalah sistem informasi berbasis web. Web digunakan karena multiplatform dan bersifat user friendly. Saat ini teknologi web juga sudah bisa diakses dari perangkat mobile. Penelitian tentang sistem informasi pernah dilakukan oleh Sri Eniyati dengan judul "Model Sistem Informasi KIA dan KB pada Puskesmas dalam Usaha Peningkatan Manajemen Layanan Kesehatan Masyarakat ".

Penelitian tersebut membuat sebuah model sistem informasi untuk meningkatkan pelayanan dapa puskesmas yang selama ini hanya menggunakan layanan konvensional, yang menyebabkan pelayanan tidak maksimal. Penelitian selanjutnya yaitu dilakukan oleh Tenia Wahyuningrum dengan judul "Implementasi dan Pengujian Web E-commerce untuk Produk Unggulan Desa". Penelitian tersebut menggunakan metode RAD yang terdapat tiga tahapan yaitu requirement planning, system design dan implementasi, tahap implementasi dilakukan dengan pengujian menggunakan metode black box.

Berdasarkan latar belakang tersebut dan penelitian yang sudah pernah dilakukan maka dibutuhkan penelitian ke tahapan selanjutnya yaitu tahapan implementasi dan pengujian. Sehingga sistem informasi dapat diterapkan ke internet dan dilakukan pengujian sistem informasi agar sesuai dengan spesifikasi kebutuhan sistem.

\section{TINJAUAN PUSTAKA}

Sistem adalah suatu kerangka dari prosedur-prosedur yang saling berhubungan, yang disusun sesuai dengan skema yang menyeluruh untuk melaksanakan suatu kegiatan atau fungsi utama dari perusahaan yang dihasilkan oleh suatu proses tertentu yang bertujuan untuk menyediakan informasi untuk membantu mengambil keputusan.

Menurut Sutarman (2009:5), dalam bukunya yg berjudul Pengantar Teknologi Informasi mendefinisikan sistem sebagai kumpulan elemen yang saling berinteraksi dalam suatu kesatuan untuk menjalankan suatu proses pencapaian suatu tujuan utama. Informasi menurut Agus Mulyanto (2009 : 12) adalah data yang diolah menjadi bentuk yang lebih berguna dan lebih berarti bagi yang menerimanya, sedangkan data merupakan sumber informasi yang menggambarkan suatu kejadian yang nyata. Informasi merupakan hasil pengolahan data dari suatu sumber yang kemudian diolah sehingga memiliki nilai dan manfaat.

Berdasarkan definisi yang dijelaskan, maka dapat disimpulkan bahwa sistem informasi merupakan kumpulan elemen yang saling berinteraksi dalam mengolah data dari suatu sumber sehingga dapat menghasilkan suatu informasi yang bermanfaat. PHP adalah bahasa pemrograman untuk pembuatan web yang memproses program dilingkungan web server dan bisa melakukan koneksi dengan database seperti MySQL, Oracle, SQLserver, dsb.

Untuk dapat menjalankan PHP dalam web browser maka harus di install web server seperti Apache, Xampp, atau Wampp terlebih dahulu. Hypertext Preprocessor (PHP) yaitu bahasa pemograman web server-side yang bersifat open source". PHP merupakan script yang terintegrasi dengan 
HTML dan berada pada server (server side HTML embedded scripting).

MySQL adalah tercepat, easy-to-use RDBMS banyak digunakan untuk usaha kecil dan besar. MySQL dikembangkan, dipasarkan, dan didukung oleh MySQL AB, yang merupakan perusahaan Swedia. MySQL menjadi begitu populer karena banyak alasan yang baik. MySQL yang dirilis di bawah lisensi open-source. Jadi Anda tidak perlu membayar untuk menggunakannya. Entity Relationship Diagram (ERD) merupakan suatu model data yang di kembangkan berdasarkan objek. Selain itu digunakan untuk menjelaskan hubungan antar data dalam basis data kepada pengguna secara logis.

Entity Relationship Diagram (ERD) didasarkan pada suatu persepsi bahwa real world terdiri atas obyek-obyek dasar tersebut. Penggunaan Entity Relationship Diagram (ERD) relatif mudah dipahami, bahkan oleh para pengguna yang awam.

\section{METODE PENELITIAN}

Pengembangan adalah suatu pendekatan yang sangat rapi dan berurutan untuk membuat sebuah sistem menjadi suatu kenyataan. Diperlukan suatu rancangan metodologi untuk menyediakan suatu struktur pengembangan sistem. Ada banyak siklus hidup pengembangan sistem (SDLC) "tradisional" untuk sistem informasi. Yang terdiri antara lain:

Perencanaan

Fase perencanaan memulai dengan sebuah kebutuhan bisnis yang belum terpenuhi. Meliputi peluang-peluang yang mungkin yang diidentifikasi dengan membaca lingkungan. Apakah ada suatu masalah yang harus dipecahkan? Inisiasi proyek melibatkan sebuah sistem yang telah diputuskan. Jika kelihatan bermanfaat, maka dilakukan (analisis) studi kelayakan. Studi kelayakan ini mempertimbangkan apakah gagasan tersebut masuk akal, jika disetujui maka ditugaskanlah seorang manajer proyek ntuk menyusun sebuah rencana kerja, mengorganisasi proyek, dan mengadopsi metode-metode untuk mengelolanya.

Analisis

Fase analisis seperti wawancara pada kontraktor. Fase ini menanyakan dan menjawab pertanyaan-pertanyaan penting seperti siapa para pengguna system, apa yang akan dicapai oleh system, dan dimana dan kapan system akan dijalankan. Fase ini memulai dengan mengembangkan sebuah strategi analisis atau suatu rencana untuk memandu proyek. Jika sebelumnya sudah ada sistem yang berjalan, maka sistem tersebut dianalisis bersama dengan berbagai cara untuk mengarah kepada sistem yang baru. Hal ini memimpin kepada pengumpulan informasi lebih lanjut, pengembangan subuah model proses dan model data.

Desain

Fase desain menandai bagaimana sistem akan bekerja, mempertimbangkan semua detail perangkat keras, perangkat lunak, infrastruktur jaringan, antar muka pengguna, dan seterusnya. Pada fase ini antarmuka pengguna, form, display, program dan laporan, database dan file ditetapkan.

Implementasi

Fase ini merupakan tempat dimana sistem dibangun. Kontruksi melibatkan tidak hanya membangun sistem, tetapi juga mengujinya untuk memverifikasi bahwa sistem bekerja. Instalasi merupakan langkah terakhir dan melibatkan apakah sistem benar-benar berjalan.

\section{HASIL DAN IMPLEMENTASI}

Tahapan implementasi merupakan tahapan membawa hasil perancangan ke dalam bahasa pemrograman. Sistem Informasi Pengaduan Inventaris Kelas merupakan sistem yang berbasis web sehingga menggunakan bahasa pemrograman php dan database mysql.

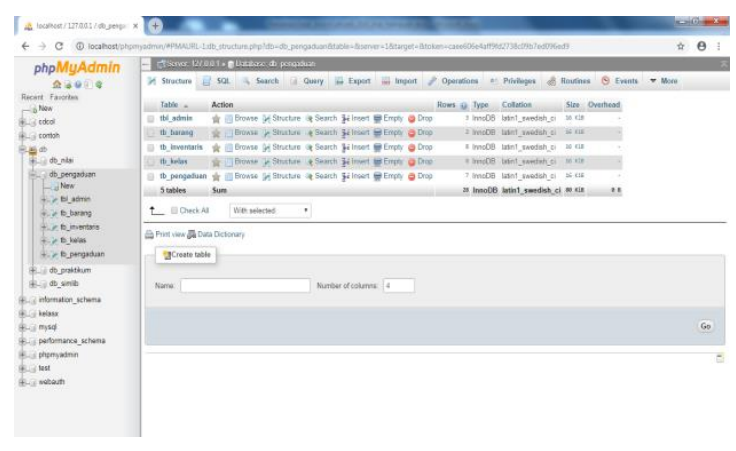

Gambar 1. implementasi database 


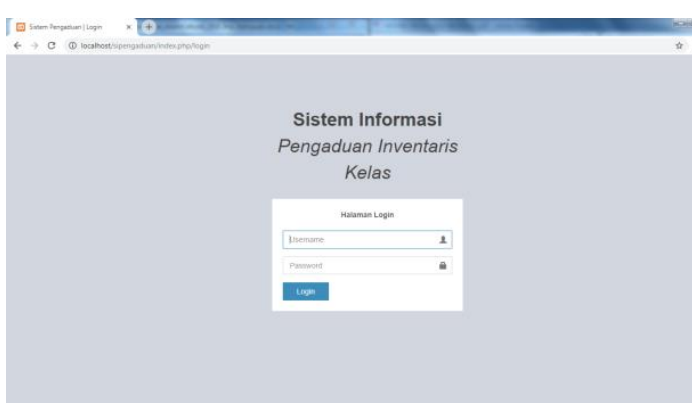

Gambar 2. Implementasi sistem

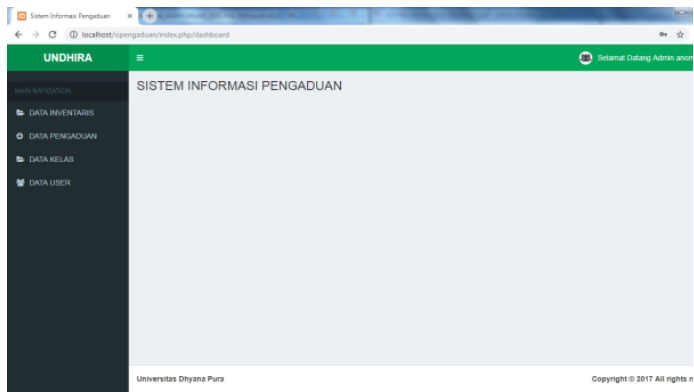

Gambar 3. Halaman admin

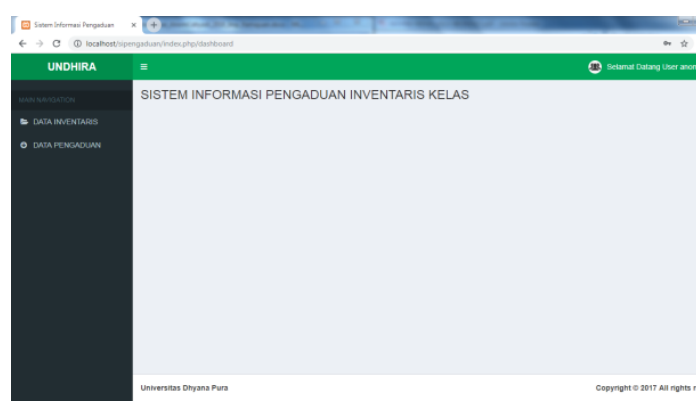

Gambar 4. Halaman user

Berikut ini hasil pengujian sistem menggunakan metode black box berdasarkan pada blok pengujian sistem:

Tabel 1. Pengujian login

\begin{tabular}{|c|c|c|}
\hline Data Masukan & $\begin{array}{l}\text { Yang } \\
\text { Diharapkan }\end{array}$ & Status \\
\hline $\begin{array}{l}\text { Username dan } \\
\text { password } \\
\text { yang } \\
\text { diinputkan } \\
\text { salah }\end{array}$ & $\begin{array}{l}\text { Akan } \\
\text { menampilkan } \\
\text { pesan kesalahan } \\
\text { "username atau } \\
\text { password salah" }\end{array}$ & $\begin{array}{l}{[\mathrm{v}]} \\
\text { sukses } \\
{[\quad]} \\
\text { gagal }\end{array}$ \\
\hline $\begin{array}{l}\text { Username dan } \\
\text { password } \\
\text { yang } \\
\text { diinputkan } \\
\text { kosong }\end{array}$ & $\begin{array}{l}\text { Akan } \\
\text { menampilkan } \\
\text { pesan kesalahan } \\
\text { "username atau } \\
\text { password } \\
\text { kosong" }\end{array}$ & $\begin{array}{l}{[\quad]} \\
\text { sukses } \\
{[\mathrm{v}]} \\
\text { gagal }\end{array}$ \\
\hline $\begin{array}{l}\text { Username dan } \\
\text { password } \\
\text { yang } \\
\text { diinputkan } \\
\text { benar }\end{array}$ & $\begin{array}{l}\text { Akan } \\
\text { menampilkan } \\
\text { halaman sesuai } \\
\text { dengan tingkat } \\
\text { user login }\end{array}$ & $\begin{array}{l}{[\mathrm{v}]} \\
\text { sukses } \\
{[\quad]} \\
\text { gagal }\end{array}$ \\
\hline
\end{tabular}

Username dan Akan [ v ]

password menampilkan sukses

yang

diinputkan

pesan "Akun

[ ]

salah berturut-

anda diblokir. gagal

turut selama hubungi admin"

tiga kali

Tabel 2. Pengujian tambah data barang

\begin{tabular}{|lll|} 
Data & Yang Diharapkan & Status \\
Mamukan & & \\
Tambah data & Akan muncul & {$[\mathrm{v}]$} \\
dengan & pesan informasi & sukses \\
kondisi & bahwa field & {$[$ ] } \\
dimana salah & wajib untuk diisi & gagal \\
satu field & & \\
masih kosong & & \\
\hline $\begin{array}{l}\text { Tambah data } \\
\text { barang }\end{array}$ & Akan & menampilkan \\
dengan & halaman data & sukses \\
kondisi & yang berisi data & gagal \\
semua field & barang yang & \\
terisi & sudah tersimpan & \\
\hline
\end{tabular}

Tabel 3. Pengujian tambah data pengaduan

\begin{tabular}{|c|c|c|}
\hline Data Masukan & $\begin{array}{l}\text { Yang } \\
\text { diharapkan }\end{array}$ & Status \\
\hline $\begin{array}{l}\text { Input data } \\
\text { pengaduan } \\
\text { dengan } \\
\text { kondisi salah } \\
\text { satu field } \\
\text { kosong }\end{array}$ & $\begin{array}{l}\text { Akan muncul } \\
\text { pesan informasi } \\
\text { bahwa field } \\
\text { wajib untuk diisi }\end{array}$ & $\begin{array}{l}{[\mathrm{v}]} \\
\text { sukses } \\
{[\quad]} \\
\text { gagal }\end{array}$ \\
\hline $\begin{array}{l}\text { Input data } \\
\text { pengaduan } \\
\text { dengan } \\
\text { kondisi semua } \\
\text { field terisi }\end{array}$ & $\begin{array}{l}\text { Akan } \\
\text { menampilkan } \\
\text { halaman data } \\
\text { yang berisi data } \\
\text { pengaduan } \\
\text { sudah tersimpan }\end{array}$ & $\begin{array}{l}{[\mathrm{v}]} \\
\text { sukses } \\
{[\quad]} \\
\text { gagal }\end{array}$ \\
\hline
\end{tabular}

Tabel 4. Pengujian halaman data pengaduan

\begin{tabular}{|c|c|c|}
\hline Data Masukan & $\begin{array}{l}\text { Yang } \\
\text { diharapkan }\end{array}$ & Status \\
\hline $\begin{array}{l}\text { Menampilkan } \\
\text { Data } \\
\text { Pengaduan dari } \\
\text { user }\end{array}$ & $\begin{array}{l}\text { Akan } \\
\text { menampilkan } \\
\text { seluruh data } \\
\text { dalam bentuk } \\
\text { tabel }\end{array}$ & $\begin{array}{l}{[\mathrm{v}]} \\
\text { sukses } \\
{[\quad]} \\
\text { gagal }\end{array}$ \\
\hline $\begin{array}{l}\text { Input data } \\
\text { pengaduan } \\
\text { dengan kondisi } \\
\text { salah satu field } \\
\text { kosong }\end{array}$ & $\begin{array}{l}\text { Akan muncul } \\
\text { pesan informasi } \\
\text { bahwa field } \\
\text { wajib untuk } \\
\text { diisi }\end{array}$ & $\begin{array}{l}{[\mathrm{v}]} \\
\text { sukses } \\
{[\quad]} \\
\text { gagal }\end{array}$ \\
\hline $\begin{array}{l}\text { Input data } \\
\text { pengaduan }\end{array}$ & $\begin{array}{l}\text { Akan } \\
\text { menampilkan }\end{array}$ & $\begin{array}{l}\mathrm{v}] \\
\text { sukses }\end{array}$ \\
\hline
\end{tabular}




\begin{tabular}{|lll|}
\hline dengan kondisi & halaman data & {$[\mathrm{J}$} \\
semua field & yang berisi data & gagal \\
terisi & pengaduan & \\
& sudah \\
& tersimpan \\
\hline
\end{tabular}

Tabel 5. Pengujian cetak laporan

\begin{tabular}{|lll|} 
Data & Yang & Status \\
Masukan & diharapkan & \\
\hline Tombol & Akan & [ v ] \\
cetak & memunculkan & sukses \\
laporan di & data laporan & [ ] gagal \\
tekan & dengan format & \\
& pdf & \\
\hline
\end{tabular}

\section{SIMPULAN}

Hasil yang dicapai terkait dengan analisis, perancangan dan implementasi sistem pengaduan inventaris ,maka didapat kesimpulan, Mengetahui hasil pengujian dengan menggunakan metode blackbox dimana hasilnya adalah sesuai dengan yang diharapkan, Implementasi sistem dengan berbasis web dengan mengunakan bahasa pemrograman php dan database mysql

\section{DAFTAR PUSTAKA}

[1] Afyenni, Rita. 2010. Perancangan Data Flowdiagram untuk sistem informasi sekolah.

[2] Agus Mulyanto. 2009. Sistem Informasi. Yogyakarta.

[3] Aji Supriyanto. 2005. Pengantar Teknologi Informasi. Salemba Informatika, Jakarta

[4] Anhar. 2010. Panduan Menguasai PHP dan Mysql. Jakarta: Media Kita.

[5] Eniyati, Sri. 2014. Model Sistem Informasi K.I.A dan K.B pada Puskesmas dalam Usaha Peningkatan Manajemen Layanan Kesehatan Masyarakat, Jurnal Teknologi Informasi DINAMIK volume 19, No 1, Hal 24-33

[6]Hartono Jogiyanto, MBA, Ph.D., 1999, Pengenalan Komputer, Andi, Yogyakarta
[7]Herry Sofyan.,Budi Santosa, HandOut Sistem Basis Data, Jurusan Teknik Informatika

[8]Kadir Abdul, 2003, Konsep dan Tuntunan Praktis Basis Data. Andi, Yogyakarta.

[9]Kadir Abdul, 2003, Pengenalan Sistem Informasi. Andi, Yogyakarta.

[10] Pressman Roger S, Ph.D., 2002, Rekayasa Perangkat Lunak Pendekatan Praktisi (Buku Satu), Andi, Yogyakarta.

[11] Siagian, Sondang P. 2014. Sistem Informasi Manajemen Edisi 2. Jakarta: Bumi Aksara.

[12] Simarmata, Janner \& Paryudi, Imam. 2005. Basis Data (Edisi Pertama). Yogyakarta: Andi.

[13] Tenia Wahyunningrum, 2015. Implementasi dan Pengujian Web E-commerce untuk Produk Unggulan Desa, Jurnal Komputer Terapan, Volume 1, No.1, Hal 5766 